\title{
ANALYSIS OF WING SEPARATION AND MID-AIR BREAKUP IN LIGHT TRAINING AIRCRAFT
}

\author{
Matthew HIRABAYASHI (1D * \\ Department of Ophthalmology, University of Missouri Columbia, Columbia, USA \\ Received 9 November 2020; accepted 5 April 2021
}

\begin{abstract}
Despite increasing discussions concerning the recently published wing spar airworthiness directive (AD) that affects many training aircraft and several current ADs for wing struts, there remains limited objective literature on incidents of wing separation or mid-air breakup. This paper attempts to report and analyse instances of wing separation and mid-air breakup of light training aircraft. A careful review of the United States National Transportation Safety Board (NTSB) aircraft accident database revealed that wing separations were more likely occur as mid-air breakup in PA28s than 172s/182s (OR: 3.06, $95 \% \mathrm{CI}: 1.3682$ to $6.8536, \mathrm{p}=.008)$. Additionally, wing separations were less likely to occur as mid-air breakups in the strutted $172 \mathrm{~s} / 182 \mathrm{~s}$ than $177 \mathrm{~s} / 210 \mathrm{~s}$ that don't have a wing strut (OR: $0.11,95 \% \mathrm{CI}: 0.04$ to $0.29, \mathrm{p}=<.001$ ). This implies that non-strutted wing designs may be more susceptability to mid-air breakup than the strutted design of similar aircraft.
\end{abstract}

Keywords: general aviation, safety, mid-air breakup, wing separation, wing spar, training aircraft.

\section{Introduction}

With the publication of several recent airworthiness directives (ADs), a lot of attention has been drawn to the wing spar of the Piper PA-28 platform (PA28) (Sciortino, 2021). PA28 collectively includes the "Cherokee", "Warrior" "Archer", and "Arrow" models (among others) many of which are common single engine piston training aircraft. The 2018 tragedy in the Piper Arrow (PA28R) that experienced sudden departure of the left wing at 900 ' resulting in two fatalities was underscored by the fact that it was a seemingly "random" accident. The aircraft was maintained to standards by a reputable flight school, operated in visual meteorological conditions (VMC) within limitations, and during a normal phase of flight. In this way it differed from many other accidents that may involve unexpected encounter with weather, unauthorized aerobatic maneuvering, or involvement of drugs or alcohol. Accidents like this may feel uncomfortable as they seem unavoidable. There is of course always a reason behind an accident. In this case, the cause was wing spar fatigue in an area that is not easily accessible for visual evaluation on annual or 100 hour inspections (National Transportation Safety Board, 2018). The AD in response to this accident requires examination for metal fatigue cracking in the lower wing spar cap by instillation of new inspection panels (Sciortino, 2021). The PA28 platform is not alone though in the discussion of wing attachment related airworthiness directives. An AD was recently issued affecting thousands of Cessna aircraft that addressed wing strut attachment to the fuselage (Gant, 2020a). This too affected many training and common general aviation (GA) aircraft including the Cessna 172 Skyhawk (C172) and Cessna 182 Skylane (C182), also single engine piston aircraft. This $\mathrm{AD}$ specifically addressed the fatigue near the wing strut of the aircraft which is a structure extending from fuselage to wing. This braced vs. cantilever (non-strutted) design of the PA28 line provides additional integrity to the wing attachment. Cessna does offer cantilever high wings in a similar design to the strutted versions including the Cessna 177 Cardinal (C177) and Cessna 210 Centurion (C210). Interestingly, these aircraft have also been the center of concern regarding wing spar integrity after midair breakup of a C210 due to metal fatigue for which the FAA released a mandatory visual and eddy current inspection of the wing spars on these models, reminiscent of the current AD (Gant, 2020b).

Among the top 10 causes of GA accidents, "System Component Failure - Non-Powerplant" (the category under which structural failures would fall) ranks \#6 in frequency for cause of accidents according to the FAA (Dorr, 2018). The current data supports a modest improvement in GA safety over the past few decades and while new

*Corresponding author. E-mail: matt@eyeflymd.com

Copyright $\odot 2021$ The Author(s). Published by Vilnius Gediminas Technical University

This is an Open Access article distributed under the terms of the Creative Commons Attribution License (https://creativecommons.org/licenses/by/4.0/), which permits unrestricted use, distribution, and reproduction in any medium, provided the original author and source are credited. 
technology may be improving situation awareness and overall safety, the high price of these more advanced aircraft means that old airframes (prone to metal fatigue from decades of flight) are likely to remain in the sky for years to come (Boyd, 2017). While the Ballistic Parachute Recovery System (BPRS), made popular by Cirrus, has demonstrated effectiveness in reducing fatality after a wide variety of accident conditions but these systems are expensive to maintain and expensive to retrofit in older aircraft (Alaziz et al., 2017). These aging training aircraft are currently operated past the service life for which they were originally designed so there is an inherent concern for structural integrity (Jaya et al., 2010). Due to this, it's reasonable to expect more of these ADs focused on fatiguing metal to spring up in the future and data on accidents in the common training aircraft is important to help assess the appropriateness of the $\mathrm{ADs}$ and safety of the aircraft in general. The high rate of GA accidents compared to that of airlines is a discrepancy that has existed for many years and studies and interventions directed at reducing the rate should be a priority ( $\mathrm{Li}$ \& Baker, 2007). While it has been reported that accidents involving operations outside of weight and balance limitations have remained static for some time, there is no data investigating structural failures occurring while complying with aircraft limitations (Boyd, 2016). A review of existing literature also fails to produce any work that specifically evaluates the numbers of wing separation events like those that prompted the aforementioned ADs.

Analysis of the numbers is valuable as it would provide data from which individuals and regulating bodies may inform conclusions about the appropriateness of the ADs or general safety of the strutted vs. cantilever design.

The aim of this report was to investigate how many times a wing separated (especially in an "unexpected" fashion) for the common trainers mentioned above and if there were any differences between the low, cantilever wing and high, strutted wing design. The cantilever counterparts to the common Cessna trainers were also evaluated to determine if any difference in wing separation frequency exists between similar air frames based on the presence of a strut.

\section{Methods}

Author MH performed a search of the United States National Transportation Safety Board (NTSB) aircraft accident records (National Transportation Safety Board, 2001). The NTSB aircraft accident database contains records of civil accidents and incidents involving aircraft in the United States, its territories, and international waters from 1962 to present. This search was done before the CAROL system (Case Analysis and Reporting OnLine) was implemented on 11/03/2020 for records 2008 and later (National Transportation Safety Board, 2020). A similar search that includes 2008 and later can still be performed using the aviation database and will yield all the public records from which this data was derived (Aviation Database, 2001).
The thorough search was done for the PA28, C172, C182, C177, and C210 models using Piper or Cessna for make as appropriate. The following terms were used for individual text searches in the narratives:

1. Wing separation.

2. Wing separated.

3. Wing departure.

4. Wing departed.

5. Breakup.

6. Break up.

The PDFs for the individual accident reports were viewed on the NTSB website and the following variables were collected based on careful review of the accident report text and recorded in Microsoft Excel:

1. Model (PA28, C172, C182, C177, or C210).

2. In-Air Wing Separation vs. Post-Collision Separation.

3. Engine Loss Implicated as Cause of Accident or not.

4. Weather Implicated as Cause of Accident or not.

5. Drugs Implicated as Cause of Accident or not.

6. The Accident Resulted in No or Any Fatalities.

7. If the Wing Separation was "Insidious" or not Defined as Wing Separations Occurring:

a) in aircraft maintained to standard,

b) within operating limitations,

c) during a normal phase of flight,

d) in visual meteorological conditions (VMC).

These variables were chosen as they represent some of the broad categories by which the NTSB groups probable cause of aircraft accident. Several causes may contribute to an accident and some categories are very broad (e.g. engine loss may itself be due to several underlying causes such as mechanical problems or fuel starvation). Any duplicate data was eliminated. As mentioned above, the PA28 model line includes the Cherokee, Warrior, Archer, and Arrow models (among others) including their variations (e.g. PA28-180 Archer and PA28-181 Archer III). Many of these are common training aircraft. For a comparison, data for the C172 and C182 were included since they are also common training aircraft and reasonable counterparts in terms of horsepower and complexity to many variants of the PA28 platform. The $\mathrm{C} 177$ and $\mathrm{C} 210$ were included due to their cantilever wing so analysis could be conducted between two differing Cessna wing configurations on a similar airframe.

Wing separation is likely in a wide variety of circumstances. The search by text string in the accident report narrative included records of aircraft that lost a wing for any reason including due to striking the ground at the final crash site as well as accidents on the taxiway. Data on mid-air vs post-collision breakups was specifically collected to differentiate them from the wing departing due to colliding with an object (e.g. trees, power lines, etc.), or the terrain on final impact.

Statistical analysis was performed in SPSS v24 and included chi-square analysis with calculation of Odds Ratios.

The method of this study has several limitations. There is limited standardization by the NTSB with changes in 
reporting format over time and the limitation of the data beginning in 1962. Additionally, cases may be missing but the search terms returned a large number of records from the NTSB Aircraft Accident Database that were all manually reviewed for appropriate inclusion. The NTSB also has a limited scope to the United States, its territories, and international waters. Accidents outside of the scope are not included in the analysis and there may be different practices in terms of maintenance and different accident patterns in other countries. Lastly, a great number of aircraft models are not included in this analysis such as smaller training platforms including the Cessna 150 or Piper PA38 Tomahawk.

\section{Discussion on results}

\subsection{Consideration of PA28 accidents}

In all 114 cases of a wing departing or in-flight breakup of a PA28 there were two instances of insidious wing separation. The first was in 1987 when a PA28-181 was performing survey work for a pipe company (National Transportation Safety Board, 1987). During normal cruise flight in VMC, the left wing departed. Analysis after the accident showed fatigue on the wing spar to be the underlying reason. A 10-inch-long crack that had been stop-drilled in the upper wing skin was also found. There were 7490 hours on the airframe. In response, the FAA issued AD 87-08-08 that required the replacement of any wing spars found to be cracked as well as the visual inspection of the upper wing skins for cracks. In May 1989, the FAA issued AD 87-08-08R3 which rescinded the original $\mathrm{AD}$ and its revisions (Perry, 1989).

The second instance of insidious wing separation is the case referenced in the introduction. In 2018, A PA28R departed from a touch and go when the left wing separated. Again, wing spar fatigue was the underlying cause and there were 7,690.6 airframe hours and 33,276 landing cycles (National Transportation Safety Board, 2018). This flight was also in a well-maintained aircraft, in VMC, under normal operating conditions, during a normal phase of flight.

In the PA28 platform, 39 (34.2\%) of the wing separations were mid-air breakups, they occurred before the aircraft or wing collided with an object or terrain. Other than the 2 insidious wing separations, the remaining midair breakups were determined to be due to exceeding the operating limitations of the aircraft (due to loss of control, unsafe maneuvering, etc.) or a mid-air collision.

\subsection{Consideration of $\mathrm{C} 172$ accidents}

In the 42 wing separations/breakups in the $\mathrm{C} 172$, there were no cases of a wing departing an insidious manner. Worth mentioning, a wing did separate from a 172 during a normal phase of flight within operating limitations on 11/29/2002 and this was due to a missing nut that secures the right wing's strut to the fuselage (National Transportation Safety Board, 2002). This is perhaps equally concerning as it represents and aircraft that received a recent annual and was reasonably believed to be airworthy but was indeed a result of a maintenance error.
In the remaining $\mathrm{C} 172$ accidents evaluated, 6 (14.3\%) of the wing separations were mid-air breakups, they occurred before the aircraft or wing collided with an object or terrain. The mid-air breakups were determined to be due to exceeding the operating limitations of the aircraft (due to loss of control, unsafe maneuvering, etc.) or a midair collision.

\subsection{Consideration of $\mathrm{C} 128$ accidents}

In the 20 reviewed wing separations/breakups of a C182, there were no insidious cases. Worth noting, 15 (75.0\%) of wing separation were due to colliding with trees or elevated terrain and $10(50.0 \%)$ involved an encounter with weather.

In the remaining C182 accidents evaluated, 2 (10.0\%) of the wing separations were mid-air breakups, they occurred before the aircraft or wing struck an object or terrain. Worth specifically mentioning due to the oddity of the scenario, one of the wing separation occurred after a C182 collided with another aircraft during a skydiving operation and since all involved were wearing personal parachutes there were no fatalities (National Transportation Safety Board, 2013). The other was loss of control and subsequent maneuvering outside of the aircraft's limitations.

\subsection{Consideration of $\mathrm{C} 177$ accidents}

In the $\mathrm{C} 177$, there were 4 wing separations/breakups in the NTSB database. These were mostly collisions. Only one of them was a mid-air breakup from exceeding airspeed limitations. None of the wing separations were insidious.

\subsection{Consideration of C210 accidents}

In the 27 cases evaluated in the $\mathrm{C} 210$, there was a single case of an insidious mid-air breakup for an unknown reason. In $1 / 21 / 97,12$ feet of the right wing departed and the cause was not definitively established (National Transportation Safety Board, 1997). The report does include that "Examination of the airframe, engine, and components failed to reveal preexistent anomalies". It's possible turbulence or ice was a factor but there is no mention of specific fatigue as in the PA28 reports.

In the remaining C210 accidents evaluated, 18 (66.7\%) of the wing separations were mid-air breakups, they occurred before the aircraft or wing struck an object or terrain. The mid-air breakups were determined to be due to exceeding the operating limitations of the aircraft (due to loss of control, unsafe maneuvering, etc.) or a mid-air collision.

\subsection{Comparison analysis}

Some select comparisons were performed. In cases of wing separation, it was evaluated if there was a relationship between aircraft type and if the aircraft experienced a mid-air breakup (e.g. after loss of control, turbulence etc.) or the wing separated after striking an object (e.g. trees, towers etc.) or terrain (i.e. final crash site on the ground). PA28s were compared to $\mathrm{C} 172 \mathrm{~s} / \mathrm{C} 182 \mathrm{~s}$ because again, they are in many respects comparable platforms, common trainers, 
and collectively represent similar levels of complexity. Midair breakups accounted for 39 (34.2\%) of the wing separations in PA28s and 9 (14.5\%) of C172s/C182s (Table 1). This was a statistically significant difference (OR: 3.06, $95 \%$ CI: 1.3682 to $6.8536, p=.008)$. Based on these data, in cases of wing separation a PA28 was roughly 3 times more likely to have that separation associated with a midair breakup compared to a C172/C182.

Table 1. Mid-air breakups vs. post-collision wing separations between PA28s and C172s/C182s

\begin{tabular}{|l|c|c|}
\hline Nature of Wing Separation & PA28 & C172/C182 \\
\hline Breakup & 39 & 9 \\
\hline Post-Collision & 75 & 53 \\
\hline Total & 114 & 62 \\
\hline
\end{tabular}

The same scenario was also evaluated between C172s/ $\mathrm{C} 182 \mathrm{~s}$ and $\mathrm{C} 177 \mathrm{~s} / \mathrm{C} 210 \mathrm{~s}$ as a matter of interest between the strutted vs. cantilever design.

Mid-air breakups accounted for 9 (14.5\%) of C172s/ C182s and $19(61.3 \%)$ of the wing separations in C177s/ $\mathrm{C} 210$ s (Table 2). This was a statistically significant difference (OR: $0.11,95 \%$ CI: 0.04 to $0.29, p=<.001$ ). Based on these data, in cases of wing separation a C177/C210 was roughly 10 times as likely to have that separation associated with an in-flight, mid-air breakup compared to a C172/C182.

Table 2. Mid-air breakups vs. post-collision wing separations between C172s/C182s and C1772/C210s

\begin{tabular}{|l|c|c|}
\hline Nature of Wing Separation & C172/C182 & C177/C210 \\
\hline Breakup & 9 & 19 \\
\hline Post-Collision & 53 & 12 \\
\hline Total & 62 & 31 \\
\hline
\end{tabular}

This is presented in Figure 1 and conditions associated with wing separations in various platforms are displayed in Figure 2 (C177 is excluded due to low sample size). The reason percentages do not add up to $100 \%$ is because the NTSB reports often include multiple factors contributing to the accident so each factor was included if it was implicated in the final NTSB accident report.

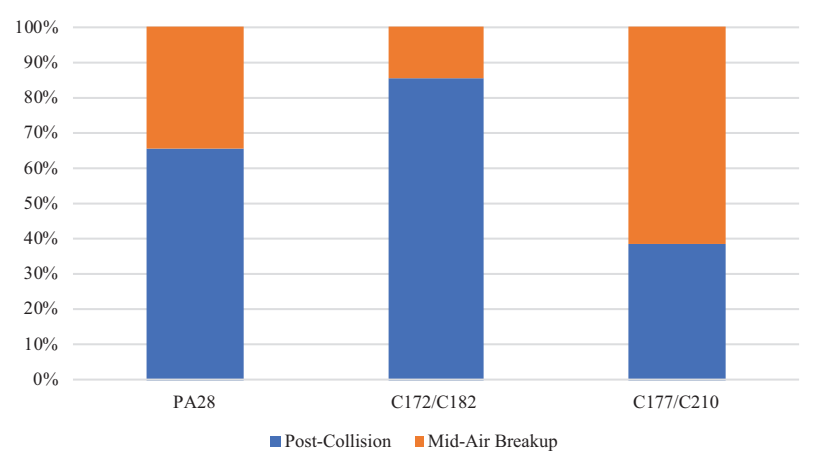

Figure 1. Post-collision vs. mid-air breakups in PA28s, C172/ C182s, and C177s/C210s

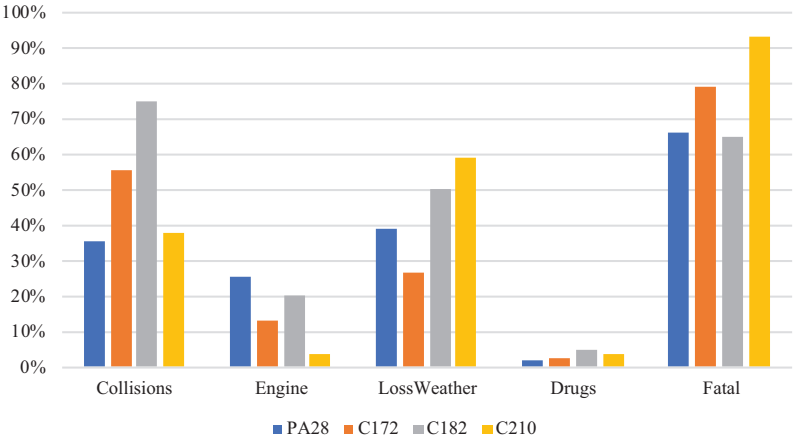

Figure 2. Percentage of events contributing to wing separations and fatalities in PA28s, C172s, C182s, and C210s

\section{Conclusions}

This study is the first to evaluate objective data on wing separations/mid-air breakups of common training aircraft based on United States NTSB archive and can provide objective evidence to pilots, manufacturers, and governing authorities on the frequency and circumstances surrounding wing separation events. Hazard Identification \& Risk Mitigation is a valuable retrospective tool while providing data with which prediction can be drawn to avoid further accidents. Two instances of a well-maintained PA28 aircraft maneuvering within operating limitations during a normal phase of flight in VMC that experienced wing separation were located in the NTSB record. There is also a case of a C172 thought to be maintained to standard with a recent annual experiencing a similar wing separation due to a maintenance error and a case of a C210 experiencing a right wing departure for inconclusive reasons. The $\mathrm{C} 172$ case particularly underscores the importance of reliable maintenance as a missing bolt was sufficient to destabilize the structure and result in spontaneous wing separation. In the two cases of the PA28s though the root cause of the accident was wing spar metal fatigue that is not a routine part of maintenance inspections which is what the current $\mathrm{AD}$ addresses.

The data also suggest that a PA28 is 3 times as likely to be associated with a pre-collision, mid-air vs. post-collision wing separation compared to a C172/C182. Additionally, based on the data a C172/C182 was 1/10 as likely to be associated with a mid-air breakup vs. post-collision wing separation compared to a $1877 / \mathrm{C} 210$. In the strutted wing design it appears that wing separation before collision with terrain or other aircraft is less common compared to the cantilever design on these small trainers which may support the abundance of caution some of the ADs provide. This is also evidence that the wing strut is valuable additional security in reducing risk of a mid-air breakup involving the wing even when the aircraft is operated outside of operating limitations. Because of this, measures that optimize the standard maintenance on these aging airframes, especially those with the cantilever design, seems appropriate even if they are costly. The fleet of trainers will continue to age and metal fatigue will become a greater issue so continued updates to 
maintenance procedure to address these symptoms of age and use would be prudent.

In addition to the insidious PA28 cases, there were indeed cases in the C172 and C210 of a wing separating for equally "unexpected" reasons (inadequate maintenance and an unknown cause respectively). Updated maintenance to address the needs of an aging fleet must be accompanied by reliable maintenance.

Based on the information presented here, it certainly seems that remaining within operating limitations and avoiding weather beyond personal or aircraft capabilities is a wise decision in any circumstance. Additionally, a wing spar that is difficult to assess during regular maintenance might not benefit from an $\mathrm{AD}$ if there are errors in the maintenance itself. Future studies would be helpful to evaluate the root cause of some precipitating factors (e.g. loss of control) and further analysis on the technology available (e.g. radar, autopilot, etc.) could help evaluate their role in preventing overstressing the airframe. Additionally, it would be interesting to evaluate the value of the retrofit BPRS in older aircraft.

Regardless, of the hundreds of thousands of these aircraft that have flown their millions of collective hours, wing separation and mid-air breakup is rare. It is certainly important to take every personal action possible to minimize this risk including ensuring regular maintenance, maneuvering within operating limitations, and adhering to personal and aircraft weather minimums to make them even rarer.

\section{Acknowledgements}

Author $\mathrm{MH}$ would like to acknowledge Brett Whitcomb for expert instruction and guidance.

\section{Funding}

No funding was received for this study.

\section{Author contributions}

$\mathrm{MH}$ conceived the study and was responsible for the design, collection of the data, development of the data analysis, analysis, interpretation, writing, and editing.

\section{Disclosure statement}

Author $\mathrm{MH}$ has no conflicts of interests or financial disclosures.

\section{References}

Alaziz, M., Stolfi, A., \& Olson, D. M. (2017). Cirrus airframe parachute system and odds of a fatal accident in Cirrus aircraft crashes. Aerospace Medicine and Human Performance, 88(6), 556-564. https://doi.org/10.3357/AMHP.4679.2017

Aviation Database. (2001). NTSB accident query. http://www.aviationdb.com/Aviation/AccidentQuery.shtm

Boyd, D. D. (2016). General aviation accidents related to exceedance of airplane weight/center of gravity limits. Accident Analysis \& Prevention, 91, 19-23.

https://doi.org/10.1016/j.aap.2016.02.019
Boyd, D. D. (2017). A review of General Aviation safety (19842017). Aerospace Medicine and Human Performance, 88(7), 657-664. https://doi.org/10.3357/AMHP.4862.2017

Dorr, L. (2018, July 30). Fact sheet - General aviation safety. Federal Aviation Administration (FAA), DOT. https://www.faa. gov/news/fact_sheets/news_story.cfm?newsId=21274

Gant, L. T. (2020a, August 24). Airworthiness Directives; Textron Aviation Inc. Airplanes (Docket No. FAA-2018-0049). Federal Aviation Administration (FAA), DOT. https://www.federalregister.gov/documents/2020/10/07/2020-22039/airworthiness-directives-textron-aviation-inc-airplanes

Gant, L. T. (2020b, February 13). Airworthiness Directives; Textron Aviation Inc. (Type Certificate Previously Held by Cessna Aircraft Company) (Docket No. FAA-2020-0156). Federal Aviation Administration (FAA), DOT. https://www.federalregister.gov/documents/2020/02/21/2020-03276/airworthiness-directives-textron-aviation-inc-type-certificate-previously-held-by-cessna-aircraft

Jaya, A., Tiong, U. H., Mohammed, R., Bil, C., \& Clark, G. (2010). Corrosion treatments and the fatigue of aerospace structural joints. Procedia Engineering, 2(1), 1523-1529. https://doi.org/10.1016/j.proeng.2010.03.164

Li, G., \& Baker, S. P. (2007). Crash risk in General Aviation. JAMA, 297(14), 1596-1598.

https://doi.org/10.1001/jama.297.14.1596

National Transportation Safety Board. (2020). CAROL Query. NTSB. https://data.ntsb.gov/carol-main-public/keywordsearch

National Transportation Safety Board. (1987, March 30). National Transportation Safety Board Aviation Accident Final Report (Accident No: FTW87FA088). NTSB. https://app.ntsb.gov/ pdfgenerator/ReportGeneratorFile.ashx?EventID=20001213 X30441\&AKey $=1 \&$ RType $=$ HTML\&IType $=$ FA

National Transportation Safety Board. (1997, January 21). Aviation Accident Data Summary (Accident No: CHI97FA056). NTSB. https://app.ntsb.gov/pdfgenerator/ReportGeneratorFile.ashx? EventID=20001208X07261\&AKey=1\&RType=Sum mary\&IType $=$ FA

National Transportation Safety Board. (2001). NTSB Aviation Accident Database \& Synopses. NTSB. www.ntsb.gov/_layouts/ ntsb.aviation/index.aspx

National Transportation Safety Board. (2002, November 29). Aviation Accident Final Report (Accident No: FTW03FA053). NTSB. https://app.ntsb.gov/pdfgenerator/ReportGeneratorFile.ashx? EventID=20021230X05642\&AKey=1\&RType $=$ HT ML\&IType $=$ FA

National Transportation Safety Board. (2013, November 2). Aviation Accident Final Report (Accident No: CEN14LA036). NTSB. https://data.ntsb.gov/carol-repgen/api/Aviation/ReportMain/GenerateNewestReport/88377/pdf

National Transportation Safety Board. (2018, April 4). In-flight Breakup of PIPER PA28R (Accident No: ERA18FA120). NTSB. https://www.ntsb.gov/investigations/Documents/ ERA18FA120-Investigative-Update.pdf

Perry, C. L. (1989, May 22). Airworthiness Directive; Piper PA28 and PA32 series airplanes (Docket No. AD 87-08-08 R3). Federal Aviation Administration (FAA), DOT. https://rgl.faa.gov/ Regulatory_and_Guidance_Library/rgad.nsf/0/3a805d11f753 eba78625829700556b61/\$FILE/87-08-08_Rescission.pdf

Sciortino, G. A. (2021, January 15). Airworthiness Directives; Piper Aircraft, Inc. Airplanes (Docket No. FAA-2018-1046). Federal Aviation Administration (FAA), DOT. https://www. federalregister.gov/documents/2021/01/15/2021-00044/airworthiness-directives-piper-aircraft-inc-airplanes 